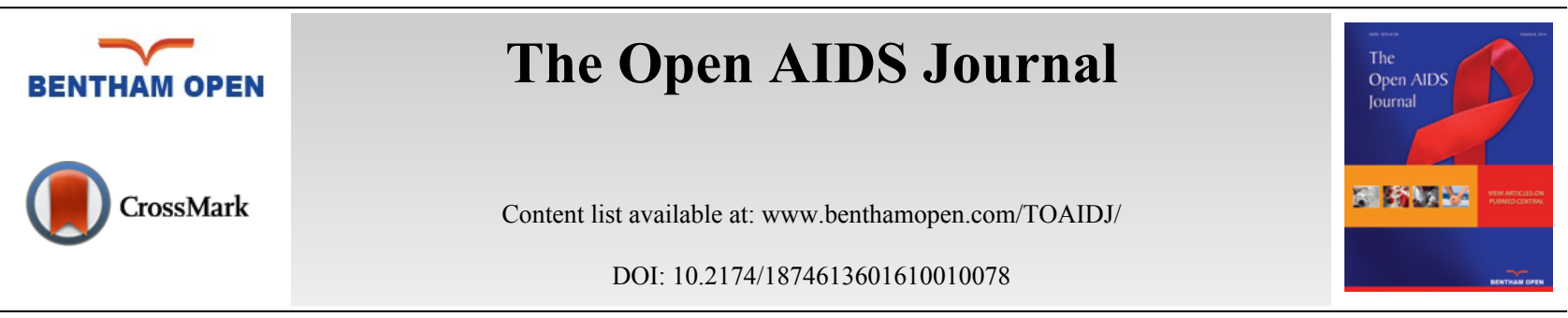

\title{
HIV Self-Testing, Self-Stigma and Haart Treatment at the University of Limpopo: Health Sciences Students' Opinion and Perspectives
}

\author{
Engetani Nkuna* and Norman Z. Nyazema* \\ Department of Pharmacy, Faculty of Health Sciences, Univeristy of Limpopo, P. Bag X 1106, Sovenga 0727, Limpopo, \\ South Africa
}

\begin{abstract}
HIV self-testing (HIVST) is an empowering process in which an individual performs an HIV rapid diagnostic test and interprets the result in privacy. Policy makers have turned to it to facilitate greater uptake, earlier diagnosis, access to prevention, care and treatment services. The University of Limpopo now has an established HIV counselling and testing (HCT) service. Unfortunately, the uptake of this HCT service by the student body is not encouraging.

It was against this background that a study was carried out among health sciences students, to assess the potential of HIVST to increase access to and uptake of HIV testing on campus. Information was gathered through focus group discussions and the social media Whatspp, among 300 health sciences students, to provide a 'yes' or 'no' response to an enquiry, about HIVST and the pregnancy test. One on one discussion on the same issues was also held with the staff at the student Health Centre which now stocks ARVs.
\end{abstract}

About $51 \%$ of the students, the majority being females indicated that they would go for the HIVST. Students' opinion and perspectives appeared to suggest that there was a potential for the HIVST to increase uptake for HIV testing.

Keywords: Diagnostic, HIV self-testing, opinion, perspectives, students.

\section{INTRODUCTION}

South Africa's National Strategic Plan on HIV, STIs and TB for the period 2012 - 2016, strategic objective 2 addresses prevention of new HIV, STI and TB infection. The following is one of the sub-objectives:

Maximise opportunity for testing and screening to ensure that everyone in South Arica is tested for HIV and screened for TB, at least annually, and appropriately enrolled in wellness and treatment, care and support programmes.

HIV self testing (HIVST), a process in which an individual performs an HIV rapid diagnostic test and interprets the result in private, is an emerging approach that is well accepted, potentially cost effective and empowering for those who may not otherwise test [1]. This idea was first proposed in the mid 1980s. During that time there were no accurate rapid diagnostic tests (RDT) and antiretroviral drugs were not widely available. The scientific world was also trying to understand HIV infection and AIDS. In recent years, given the revised World Health Organization (WHO) recommendation for earlier treatment [2], evidence that effective treatment prevents onward transmission of HIV [3], and enduring low level of testing coverage in most settings, policy makers are turning to new testing approaches to facilitate greater uptake, earlier diagnosis, and greater access to prevention, care and treatment services.

The University of Limpopo, with a student population of nearly 19,000, takes part in the First Things First (HIV/STI/TB) campaign led by the Higher Education and Training HIV/AIDS programme, HEAIDS. The mandate of HEAIDS is to develop and support HIV mitigation programmes at South Africa's public universities and further

\footnotetext{
* Address correspondence to these authors at the Department of Pharmacy, Faculty of Health Sciences, Univeristy of Limpopo, P. Bag X 1106, Sovenga 0727, Limpopo, South Africa; Email: norman.nyazema@ul.ac.za
} 
Education and Training Colleges where a lot of irresponsible sexual behaviours are observed. In fact, according to the Department of Health statistics, it is worse in schools where there were 72,891 deliveries by girls under the age of 18 from April 2012 to March 2013. A spokesperson of the Department said that issue of teenage pregnancy was just not about numbers but about the lack of use of condoms. There were 98005 abortions at state facilities in 2014 [4]. The First Things First campaign at tertiary institutions, therefore, contributes to an objective of the 2012-2016 South Africa's National Strategic Plan for HIV, STIs and TB to maximise opportunities for testing for HIV. The campaign provides for the testing using HIV rapid finger prick tests as depicted in Fig. (1) below:

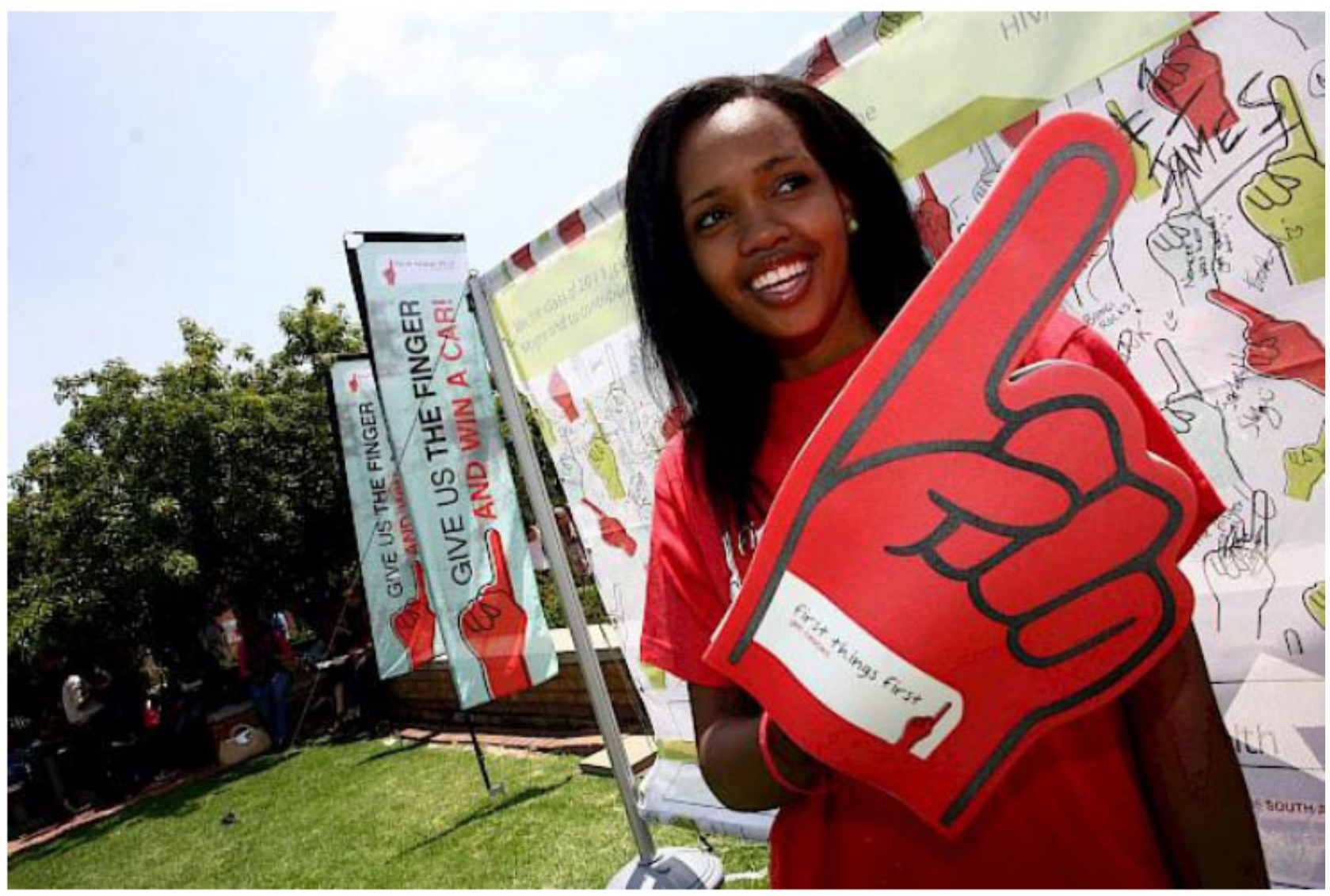

Fig. (1). A student counselling and testing promoter during the First Thing First campaign on UL campus.

The campaign at UL has been going on for more than 5 years and HIV counselling and testing (HCT) services have now been established at the campus Student Health Centre which now also stocks antiretroviral drugs, ARVs. More students tend to come for testing only during the First Things First campaign that takes place at least twice a year because there are incentives. It has been observed that, for a variety of reasons, the uptake of the HCT services by the student body is not encouraging. Only about between 2000 and 3000 out of nearly 19,000 students, mainly females, utilize the HCT services. One of the reasons that has been cited is self stigma, a belief that one is weak or damaged because of an illness, resulting in a negative attitude towards seeking or receiving the treatment. However, it has been reported that HIVST could be desirable for users concerned with stigma or confidentiality associated with existing HCT.

A study was carried out among health sciences students, mainly B Pharm, B Dietetics and B Med Sciences students, to assess the potential of HIVST to increase access to and uptake of HIV testing in order to support prevention and treatment targets on campus.

\section{METHODS}

Data were collected during the first and part of the second semester 2015. The investigation used both deductive and inductive approaches. About 300 health sciences students were asked, through the social media Whatsapp, to provide a 'yes' or 'no' response to an enquiry if they knew their HIV status and if they would use HIVST and pregnancy test. 
This was then followed by four focus group discussions with equal number of female and male students who were at different levels of their study in health sciences, in order to achieve a range of different perspectives. The discussions took place soon after a lecture on any aspect of HIV/AIDS from which a common generic research framework was established and themes for generic interview topic guides were developed. Questions included: the level of interest in HIVST, the level of sexual activity on campus, accessibility and the use of the pregnancy test, appropriate distribution channels for the HIVST kits, how to achieve linkage to treatment and care, benefits and challenges of the HIVST.

One on one discussion on the same issues was also held with the 7 staff members who included a health promoter living with HIV, at the student Health Centre which now stocks ARVs.

A 'hands on process' was used to analyse the data during its collection by creating descriptive codes and further developing interpretive codes which were finally used to come up with explanatory codes.

Using a client simulation methodology, CSM, an investigation into the sale of HIVST and pregnancy test kits was carried out on the street and at the retail pharmacies.

As shown in Table 1 below the results obtained indicated that the level of willingness to use an HIVST was not the same as the willingness to use HCT services at the student Health Centre. It would appear that most of those in the first year of their study at the university, inspite of the first things first during their first semester, were not willing to undergo an HIV test in whatever form. It was surprising that most of the final year students were not at all enthusiastic about HIV/AIDS. Only an average of about $26 \%$ would utilize the HCT services. All the students at all levels were prepared to use a pregnancy test.

Table 1. The level of willingness to use of each one of the tests among students at different levels.

\begin{tabular}{|c|c|c|c|}
\hline Level of study & HCT & HIVST & Pregnancy test \\
\hline First year & $10 \%$ & $25 \%$ & $100 \%$ \\
\hline Second year & $25 \%$ & $80 \%$ & $100 \%$ \\
\hline Third year & $20 \%$ & $60 \%$ & $100 \%$ \\
\hline Fourth year & $50 \%$ & $40 \%$ & $100 \%$ \\
\hline
\end{tabular}

The study, as shown in Table 2 , found that generally, female students were largely among those who would go for an HCT. The average was about $74 \%$.

Table 2. Shows gender differences in willingness to go for HCT.

\begin{tabular}{|c|c|c|}
\hline Level of study & Females & Males \\
\hline First year & $64 \%$ & $36 \%$ \\
\hline Second year & $80 \%$ & $20 \%$ \\
\hline Third year & $82 \%$ & $18 \%$ \\
\hline Forth year (Final year) & $68 \%$ & $34 \%$ \\
\hline
\end{tabular}

During the CSM some independent pharmacy outlets with a nurse, were selling the HIVST kits. The kits were not available in the big chain pharmacies. ARVs were available in all the pharmacies as prescription only medicines. Emergency contraceptive pill was also available and easily accessible from the pharmacies. Pregnancy test kits ranging in price from about US\$ 2 to US\$ 8 were sold in all pharmacies and on the street they were from less than US\$ 1 to US\$ 2. The investigation found that the kits were never out of stock.

Discussions with the staff at the Student Health Centre raised a concern regarding counselling and care. They pointed out that a risk certainly existed that the user of a self test might be traumatized by the test result (self stigmatization). These issues were never raised by the students. In addition the staff mentioned that HIVST might lead to the demand for more ARVs which would not be met by the Centre that was currently getting its stock from the nearby district hospital. The Centre was getting its 3 in 1 fixed dose combination of tenofovir, emetricitabine and efavirenz.

\section{DISCUSSION}

From the results obtained all indications were that there was a lot unprotected sex among students which is why the majority were comfortable with HIVST to assist in establishing their status and that some form of incentive would help. This, therefore, meant that if HIVST kits were readily available and easily accessible it would lead to earlier diagnosis 
and treatment of HIV positive students. HIVST would also assist in the 'normalisation of HIV/AIDS' and do away with term 'AIDS exceptionalism' which located the epidemic within a human rights and bioethics framework [5, 6]. It is this 'exceptionalism' which led to the development of the voluntary counselling and testing (VCT) model. VCT included pre and post-test counselling, express and informed consent that an HIV test would be conducted on the patient, and assurance of the confidentiality of the test. As time went on, after so much debate regarding 'normalization of AIDS,' VCT was replaced by the provider-initiated testing and counselling (PITC) model. The idea about 'normalization of AIDS' was that it would decrease stigma associated with the epidemic, remove the barriers to testing, increase access to treatment, and change societal perception of HIV/AIDs [7]. None of them has really decreased as the results from the study show. In general, changes in the approach, unfortunately, did not help in increasing the number of people who would want to know their HIV status, in spite of the recommendation from the South Africa's National Strategic Plan $[8,9]$. Table 3 shows some illustrative quotations regarding attitude to any form of self-testing

Table 3. Illustrative quotations discussing the tests.

\begin{tabular}{|c|c|}
\hline HCT & $\begin{array}{l}\text { - "Staff at any health facility tend to be judgemental which increases my anxiety leaving me devastated } \\
\text { and disempowered but as long as there are incentives, I do not mind" } \\
\text { - "Sometimes the in depth pretest counselling takes too long and I have not much time". I need to be in } \\
\text { class }\end{array}$ \\
\hline $\mathbf{H}$ & $\begin{array}{l}\text { - "When I do the test none knows my result but I shall seek confirr } \\
\text { shall start treating myself and ARV should therefore be readily acc } \\
\text { - "If there is some form of monetary incentive many people would }\end{array}$ \\
\hline 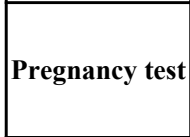 & $\begin{array}{l}\text { - "Pregnancy is a sexually transmitted condition with profound and lifelong implications, so I would nee } \\
\text { to know whether I am pregnant or not so that I can take appropriate action" } \\
\text { - "I worry more about getting pregnant than I worry about encountering HIV infection", }\end{array}$ \\
\hline
\end{tabular}

With the advent of highly active antiretroviral therapy HAART and subsequent increased access to such treatment, the $2003 \mathrm{WHO} /$ UNAIDS $3 \times 5$ initiative (treating 3 million people by 2005) would have been a resounding success had issues being raised about HIVST dealt with then. For example, self-stigmatization that is currently seen with HCT would have long been an issue of the past and the inconvenience associated with facility based HCT reduced. Students at the university indicated that they had no time for the WHO guiding principles of HCT which outline 5 Cs that must always accompany HTC: namely, consent, confidentiality, counselling, correct results and linkage to care. HIVST offered for them an opportunity for a shift in dynamics around testing session. Students indicated that the HIVST would afford them avoidance of the need for intrusive or repetitive counselling that did not meet their needs. They also said that they might decide to enrol for care and treatment at a time when personal benefit appeared to outweigh the perceived risks of accessing services. Such an action would certainly be in line with the spirit of the Patients Right Charter and the National Health Act, that both encourage people to take responsibility for their own health. Be that as it may, there is still need for addressing and accumulating more evidence on the possible uptake of counselling and testing, linkage to care and potential social harms in the context of unsupervised HIVST [10].

The investigation on the sale of HIVST kits found that they were indeed available at some pharmacy retail outlets. Self tests for HIV should fall under the definition of a 'medical device' in the Medicines and Related Substances Control Act (Act 101) of 1965, as amended). It would appear that currently there is no mechanism for the registration of medical devices that exist and therefore diagnostic tests remain unregulated. The results obtained seemed to suggest that there was no current restriction on the distribution of diagnostic tests. From the CSM the only legally binding restriction on the distribution of, for example, HIVST kits were provided by the Good Pharmacy Practice (GPP) standards issued by the South African Pharmacy Council [11]. Unfortunately the restriction, from the results obtained did not appear to be working. There is therefore a need for rethinking about the restriction in order to get evidence from those currently flouting the law and also to promote comarketing of condoms, pregnancy test and HIVST. The Department of Health launched a new scented condom for wide distribution because sexually active young people lamented that the one that was widely available did not smell 'cool'. In other words, the quality of product was addressed after the implementation of well thought condom distribution policy and enough evidence was accumulated to deal with the smelly condom. Such a post-marketing surveillance of the HIVST kits could also be done.

\section{CONCLUSION}

The study took into account students in health sciences who are supposed to be au fait with HIV/AIDS and that the 
results could not be generalized to other students at the University of Limpopo. However, there were a significant number of students who supported the introduction HVIST and did not seem concerned about possible risk associated with self-testing. What was interesting to note among female students was that they seemed concerned more about being pregnant than contracting HIV infection and appeared to be ready to know their HIV status. The student Health Centre seemed not to be ready for the introduction of HIVST. Their main concerns were possible self-stigmatization and increased demand of ARVs. A bigger study at the university involving students from other disciplines would shed more light on what people with high literacy level think about HIVST.

\section{CONFLICT OF INTEREST}

The authors confirm that this article content has no conflict of interest.

\section{ACKNOWLEDGEMENTS}

Decleared None.

\section{REFERENCES}

[1] Johnson C, Baggaley R, Forsythe S, et al. Realizing the potential for HIV self-testing. AIDS Behav 2014; 18(Suppl. 4): S391-5. [http://dx.doi.org/10.1007/s10461-014-0832-x] [PMID: 24986599]

[2] WHO. Consolidated guidelines on the use of antiretroviral drugs for treating and preventing HIV infection: recommendation for public health approach. Geneva: Available from: http://www.who.int/hiv/pub/guidelines/arv/2013/en/ [cited 201510 July];

[3] Cohen MS, Chen YQ, McCauley M, et al. Prevention of HIV-1 infection with early antiretroviral therapy. N Engl J Med 2011; 365(6): 493-505.

[http://dx.doi.org/10.1056/NEJMoa1105243] [PMID: 21767103]

[4] Govender P. Survey reveals shock teen pregnancy figures. Sunday Times 2015; 9.

[5] UN. Office of the United Nations High Commissioner for Human Rights and the Joint United Nations Programme on HIV/AIDS. Geneva: World Health Organization 2006.

[6] Kirby M. The never-ending paradoxes of HIV/AIDS and human rights Afr J Hum Rights 2004; 4(2): $163-80$.

[7] Bayer R, Fairchild AL. Changing the paradigm for HIV testing-the end of exceptionalism. N Engl J Med 2006; 355(7): 647-9. [http://dx.doi.org/10.1056/NEJMp068153] [PMID: 16914699]

[8] South Africa. Department of Health, National Strategic Plan on HIV, STIs and TB 2007-2011. Pretoria: Department of Health 2007.

[9] South Africa. Department of Health, National Strategic Plan on HIV, STIs and TB 2007-2011. Pretoria: Department of Health 2012.

[10] Pant Pai N, Behlim T, Abrahams L, et al. Will an unsupervised self-testing strategy for HIV work in health care workers of South Africa? A cross sectional pilot feasibility study. PLoS One 2013; 8(11): e79772. [http://dx.doi.org/10.1371/journal.pone.0079772] [PMID: 24312185]

[11] The South African Pharmacy Council. Good Pharmacy Practice in South Africa. $3^{\text {rd }}$ ed. Pretoria: The South African Pharmacy Council 2008.

Received: February 27, $2015 \quad$ Revised: July 9, $2015 \quad$ Accepted: October 12, 2015

(C) Nkuna and Nyazema; Licensee Bentham Open.

This is an open access article licensed under the terms of the Creative Commons Attribution-Non-Commercial 4.0 International Public License (CC BY-NC 4.0)(https://creativecommons.org/licenses/by-nc/4.0/legalcode), which permits unrestricted, non-commercial use, distribution and reproduction in any medium, provided the work is properly cited. 